\title{
Ionophoric properties of a tetra-tetrazole functionalised calix[4]arene
}

Daniel D'Alessio, ${ }^{a}$ Brian W. Skelton, ${ }^{b}$ Nigel A. Lengkeek, ${ }^{\mathrm{c}}$ Benjamin H. Fraser, ${ }^{\mathrm{c}}$ Anwen M. Krause-Heuer, ${ }^{\mathrm{c}}$ Sara Muzzioli, ${ }^{\mathrm{d}}$ Stefano Stagni, ${ }^{\mathrm{d}}$ Massimiliano Massi, ${ }^{\mathrm{a}}$ and Mark I. Ogden ${ }^{\mathrm{a}}$

a. Department of Chemistry and Nanochemistry Research Institute, Curtin University, Perth, Australia

Department of Chemistry

Curtin University

GPO Box U 1987

Perth 6845

\section{AUSTRALIA}

email: $\underline{\text { m.ogden@curtin.edu.au }}$

b. Centre for Microscopy, Characterisation and Analysis, The University of Western Australia, Crawley, Western Australia 6009, Australia

c. Lifesciences Division, Australian Nuclear Science and Technology Organisation, Locked Bag 2001, Kirrawee DC, New South Wales 2232, Australia.

d. Department of Industrial Chemistry "Toso Montanari", University of Bologna, viale del Risorgimento 4, 40126 Bologna, Italy. 


\section{Ionophoric properties of a tetra-tetrazole functionalised calix[4]arene}

The synthesis and characterisation of $p$-t-butylcalix[4]arene functionalised at the lower rim with four tetrazole moieties is reported. The macrocycle is found to be a poorer ionophore for lanthanoid cations than the bis-tetrazole substituted analogue. Solution phase photophysical studies strongly suggested that the cations interacted only weakly with the calixarene ligand. A mixed sodium / triethylammonium salt of the calixarene ligand was crystallised in the presence of lanthanoid cations and structurally characterised. Strong intramolecular interactions are hypothesised to be the cause of the observed behaviour.

Keywords: calixarene; tetrazole; lanthanide; crystal structure 


\section{Introduction}

Calixarenes, and particularly calix[4]arenes, are well established as a useful macrocyclic framework upon which to assemble ligating groups to form ionophores.(1) The most common examples introduce neutral $\mathrm{O}$ donor atoms as ester or amide moieties (2-5), or negatively charged groups such as the carboxylate (6-8), but many other variations are known $(9,10)$. We have been investigating the coordination chemistry of tetrazolates, a functional group often used as an isostere of carboxylate in medicinal chemistry, but relatively unexplored in the context of calixarene chemistry (11). Calix[4]arenes substituted with tetrazole groups at the upper rim have been reported and used for anion binding (11), and palladium coordination (12). The tetrazole moiety has also been used as a linker to attach sugars to the upper rim of a calix[4]arene (13). A calixarene has been reported with two tetrazole groups at the lower rim, and azo functional groups at the upper rim, to form a colorimetric sensor for calcium ions where binding at the tetrazole-substituted rim was proposed (14). We have reported the synthesis of a lower rim bis-tetrazole functionalised $p$-t-butylcalix[4]arene (15), which was found to form typical 1:1 complexes with lanthanoids in presence of triethylamine with the lanthanide ion occupying the lower rim cavity of the ligand (15), but when triethylamine was replaced with aqueous ammonium carboxylates crystallisation of elongated $\mathrm{Ln}_{19}$ or $\mathrm{Ln}_{12}$ clusters occurred (16).

We have now extended this work to the synthesis of a lower rim substituted tetra-tetrazole derivative, $\mathbf{1}$. We report here investigation of the interaction of this new ionophore with lanthanoid cations, and the structural characterisation of the ligand, and a mixed sodium / triethylammonium salt. 


\section{Results and discussion}

\section{Ligand synthesis and characterisation}

\section{5,11,17,23-Tetra-p-t-butyl-25,26,27,28-tetrakis(cyanomethoxy)calix[4]arene was}

synthesised via the bis-cyanomethoxy substituted precursor (17), based on the reported procedure (Scheme 1) (18). While the literature reports heating the reaction mixture to $75^{\circ} \mathrm{C}$, in our hands this resulted in substantial degradation. Stirring the reaction at room temperature improved the yield to $\sim 70 \%$ of the desired product. Conversion of the nitrile groups to tetrazole moieties was achieved using an altered Koguro method (19), as reported previously for the bis-tetrazole calixarene (15). Purification of the tetratetrazole calixarene $\mathbf{1}$ proved to be difficult, with sodium cations often retained in the product, but an analytically pure sample and crystals appropriate for a single crystal Xray structure determination were obtained by slow evaporation of an ethanol solution of 1.
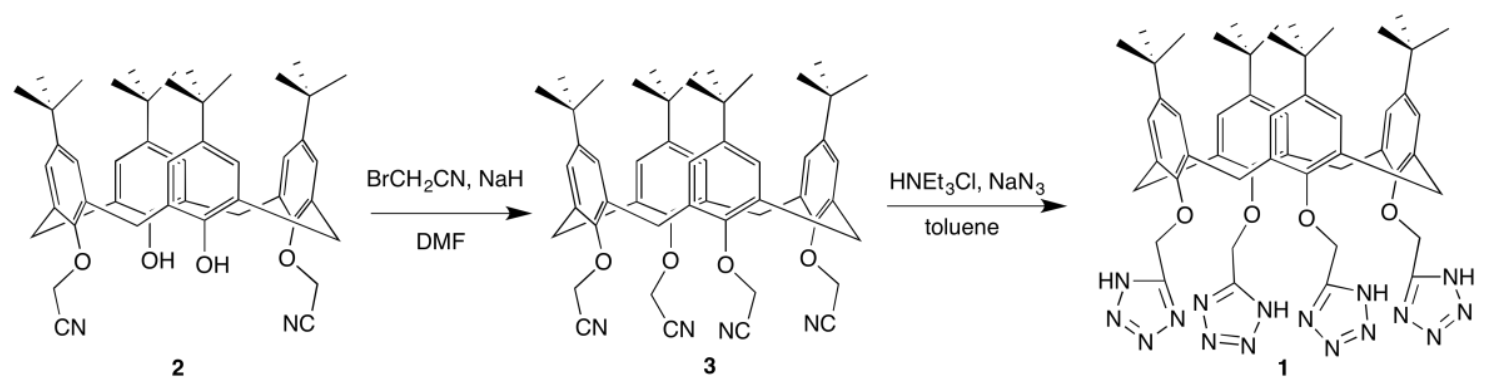

Scheme 1. Synthesis of tetra-tetrazole functionalised calixarene $\mathbf{1}$.

The results of the structure determination showed that the calixarene has the expected structure, crystallising as a solvate with one water molecule and one ethanol molecule (Figure 1). The calixarene conformation exhibits the common "pinched" distortion from the possible 4-fold symmetry with two opposite phenyl rings arranged more 'vertical' than the other opposite pair. Dihedral angles between the plane 
containing the four methylene carbon atoms and the four phenyl rings 1-4 are: 81.2(1), 49.8(1), 91.0(1), and 55.8(1) ${ }^{\circ}$. There are intramolecular hydrogen bonds between one tetrazole hydrogen atom, $\mathrm{H} 212$, and the phenoxy oxygen atom, $\mathrm{O} 41$, on the opposite group and also between the tetrazole hydrogen atom, H312, and a tetrazole nitrogen atom, N415, on an adjacent group. There are also hydrogen bonds from the remaining tetrazole hydrogen atoms to the water molecule and to the ethanol oxygen atom. The water molecule hydrogen atoms are involved in further hydrogen bonds to nitrogen atoms on molecules related by an $n$-glide plane and by a cell translation in the $a$ direction. The solvent ethanolic hydrogen atom also forms a hydrogen bond to a nitrogen atom of a molecule related by an $n$-glide thus forming a two dimensional hydrogen-bonded polymer in the ac-plane; this is shown in Fig. S1.

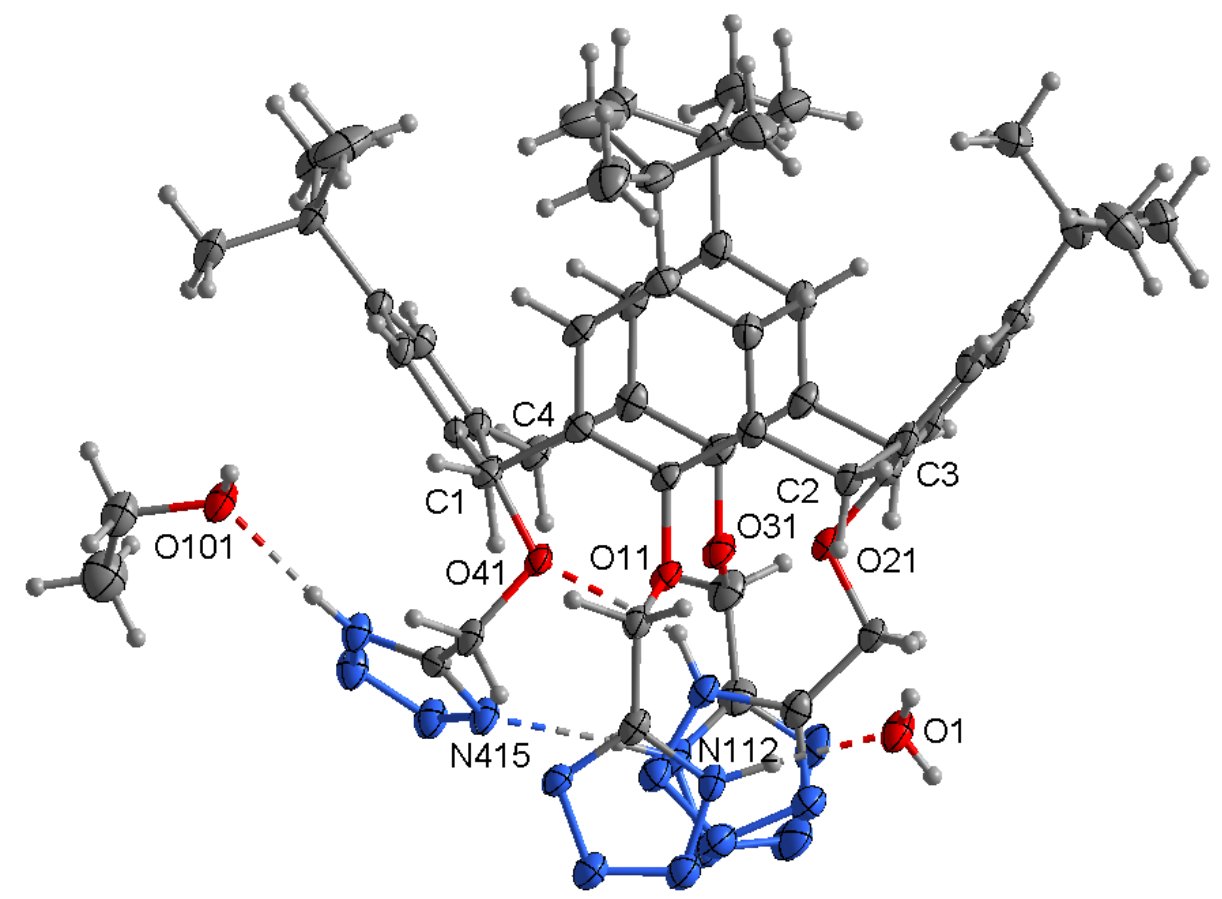

Figure 1. Molecular structure of $\mathbf{1} \cdot \mathrm{H}_{2} \mathrm{O} \cdot \mathrm{EtOH}$ projected oblique to the planes of the four methylene carbon atoms. Ellipsoids have been drawn at the $50 \%$ probability level. 


\section{Metal complexation studies}

The interaction of ligand $\mathbf{1}$ was investigated in the solution phase by probing the photophysical behaviour of solutions of $\mathbf{1}$ in the presence of lanthanoid cations and added base, typically triethylamine. In our previous studies, it was shown how the addition of triethylamine of a 1:1 solution of bis-tetrazolyl calix[4]arene and $\mathrm{Tb}^{3+}$ ions produced a significant increase in luminescence intensity and a change in the excited state lifetime.(15) Following the same experimental conditions, we have probed the photophysical behaviour of a 1:1 solution of $\mathbf{1}$ and $\left[\mathrm{Tb}\left(\mathrm{NO}_{3}\right)(\mathrm{DMSO})_{\mathrm{n}}\right]$ in dicholoromethane upon sequential addition of triethylamine (see Figures S2-S4). In this case, it is evident that the emission intensity of the $\mathrm{Tb}^{3+}$ ions remains relatively unaffected by the addition of base, with an overall photoluminescence quantum yield remaining at ca. $1 \%$. The lack of change suggests that the deprotonation of the tetrazole rings in 1 does not drive the complexation of the $\mathrm{Tb}^{3+}$ within the lower rim cavity. Furthermore, the excited state lifetime of the $\mathrm{Tb}^{3+}$ emission remains unchanged, with a monoexponential decay of ca. $1.1 \mathrm{~ms}$. Only after the addition of 6 equivalents of triethylamine, is the decay best fitted as bi-exponential with a major component of 1.1 ms (94\%) and a minor component of $0.4 \mathrm{~ms}$. However, the minor component could be due to the formation of hydroxo species caused by the addition of triethylamine and the presence of adventitious water. While the data suggest that no inclusion of the $\mathrm{Tb}^{3+}$ ions within the cavity of $\mathbf{1}$ is occurring, it can not be excluded that the $\mathrm{Tb}^{3+}$ ions are still interacting with the tetrazole moieties: in fact, the excitation spectra of the solutions, obtained by monitoring the $548 \mathrm{~nm}$ emission of the $\mathrm{Tb}^{3+}$, is analogous to the absorption spectrum of 1, indicating sensitisation via the antenna effect(20).

Consistent with the solution phase studies, attempts to crystallise lanthanoid complexes of $\mathbf{1}$ were not successful, typically resulting in isolation of the ligand alone. 
In one case, presumably caused by the presence of sodium as an impurity in $\mathbf{1}$, a mixed triethylammonium / sodium salt formed crystals appropriate for a single crystal structure determination. The results are consistent with the formulation $\left(\mathrm{HNEt}_{3}\right)_{2}[\mathrm{Na}(\mathbf{1}-$ $\mathrm{H})(1-2 \mathrm{H})] \cdot 2 \mathrm{H}_{2} \mathrm{O}$. The sodium ion is on a crystallographic inversion centre with the coordination consisting of two $\mathrm{N}$ atoms from two tetrazole groups and four water molecules. There are intramolecular hydrogen bonds between the hydrogen atoms of the coordinated water molecules and nitrogen atoms of the tetrazole rings, between the tetrazole hydrogen atoms $\mathrm{N} 215$ and N312, and also between the tetrazole hydrogen $\mathrm{H} 412$ and the calixarene oxygen atoms $\mathrm{O} 21$. The calixarene ligand thus interacts with both the primary and secondary coordination spheres of the sodium cation $(16,21)$, as shown in Figure 2. There is also an intermolecular hydrogen bond between $\mathrm{H} 115$ on N115 and the centrosymmetrically related N115. The calixarene phenyl rings again deviate considerably from possible 4-fold symmetry, with the dihedral angles between opposite phenyl ring planes being $7.91(8)^{\circ}$ (between rings $1 \mathrm{n}$ and $3 \mathrm{n}$ ) and $103.45(8)^{\circ}$ (between rings $2 n$ and $4 n$ ).

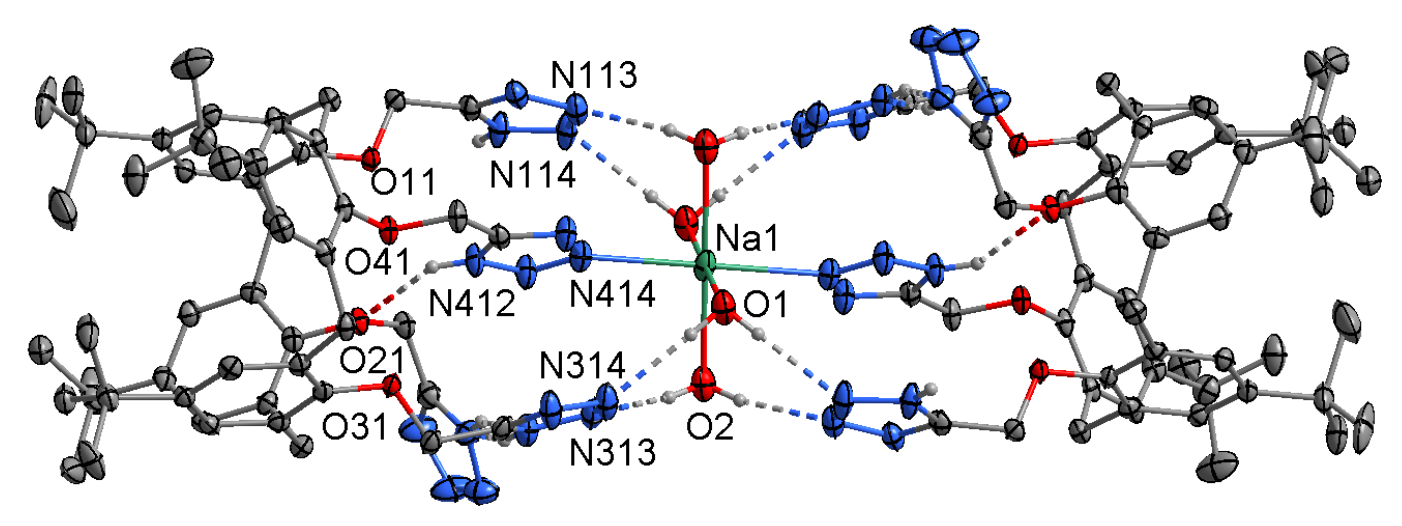

Figure 2. The structure of the anion of $1-\mathrm{Na}^{+} / \mathrm{HNEt}_{3}{ }^{+}$showing the intramolecular hydrogen bonding, with one component of the disordered atoms omitted for clarity. Ellipsoids have been drawn at the $50 \%$ probability level. 


\section{Conclusions}

A calix[4]arene substituted at the lower rim with four tetrazole moieties has been synthesised and characterised. In contrast to the known bis-tetrazole analogue, the new receptor is found to interact only weakly with lanthanoid cations under the conditions examined. Structural studies of the ligand in neutral form, and as a mixed sodium / triethylammonium salt suggest that these weak interactions might be due to extensive intramolecular hydrogen bonding.

\section{Experimental}

$1^{2}, 5^{2}$-bis(cyanomethoxy)- $3^{2}, 7^{2}$-dihydroxy- $1^{5}, 3^{5}, 5^{5}, 7^{5}$ - $t$-butylcalix[4]arene, 2, was synthesised followed the literature method (17). Proton NMR spectra for 1, 2, and $\mathbf{3}$ are shown in Figures S5-7.

\section{Synthesis of $1^{2}, 3^{2}, 5^{2}, 7^{2}$-tetra(cyanomethoxy)- $1^{5}, 3^{5}, 5^{5}, 7^{5}$-t-butylcalix[4]arene, 3}

The literature method (18) was adapted as follows. Sodium hydride (1.06 g, $44.0 \mathrm{mmol})$ and calixarene $2(2.13 \mathrm{~g}, 2.93 \mathrm{mmol})$ were added to dry DMF (100 $\mathrm{mL})$ and allowed to stir for 20 minutes. To this, bromoacetonitrile $(0.96 \mathrm{~mL}, 13.7 \mathrm{mmol})$ was added and stirred overnight at room temperature under a nitrogen atmosphere. This resulted in a black, completely opaque, solution. Water $(150 \mathrm{~mL})$ was slowly added causing a pale brown precipitate to occur, which was filtered off and washed several times with water. The solid was dissolved in a minimum amount of dichloromethane and purified by column chromatography ( silica gel, dichloromethane), to afford a white solid, 3 (1.62 g, 69\%). ${ }^{1} \mathrm{H}$ NMR (DMSO, $\delta$, ppm) 6.91 (s, 8H, Ar-H), 2.00 (s, 8H, Ar-O-CHz), 4.28 (d,

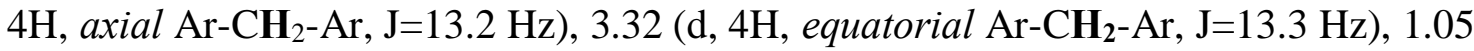

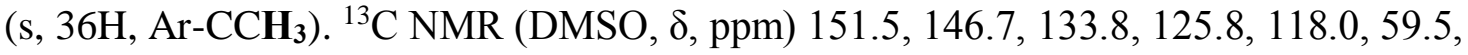
34.2, 31.7, 31.4. IR (ATR): v/ $\mathrm{cm}^{-1} 2959$ (s), 2868 (m), 1604 (w), 1473 (s), 1362 (m), 
$1190(\mathrm{~s}), 1024(\mathrm{~s}), 878(\mathrm{w})$.

\section{Synthesis of $1^{2}, 3^{2}, 5^{2}, 7^{2}$-tetra(tetrazolyl)-1 $1^{5}, 3^{5}, 5^{5}, 7^{5}$-t-butylcalix[4]arene, 1}

Toluene $(30 \mathrm{~mL})$ was placed into a round bottom flask immersed in an ice bath. To the cold solvent, triethylamine $(0.69 \mathrm{~mL}, 4.97 \mathrm{mmol})$ and hydrochloric acid $(0.48 \mathrm{~mL}, 4.97$ mmol) was added and the flask stoppered immediately. A white gas was evolved but upon stirring the solution for five minutes this dissolved into solution resulting in a white residue on the walls of the flask. Calixarene $3(0.40 \mathrm{~g}, 0.50 \mathrm{mmol})$ was then added to the solution along with sodium azide $(0.21 \mathrm{~g}, 3.2 \mathrm{mmol})$ and heated under reflux for 12 hours. The solution was cooled to room temperature and the solvent was removed under reduced pressure yielding a white solid. The residue was dissolved in ethyl acetate resulting in a cloudy pale cream solution which was filtered and washed with hydrochloric acid $(1 \mathrm{M}, 3 \times 50 \mathrm{~mL})$. The organic fraction was dried over magnesium sulfate, filtered and solvent removed by reduced pressure evaporation. The residue was washed with small amounts of cold dichloromethane to remove the coloured impurity, furnishing the tetrazole calixarene $\mathbf{1}$ as a white solid $(0.396 \mathrm{~g}, 81 \%)$. Crystals suitable for single crystal X-ray structure determination were obtained by slow evaporation of an ethanol solution of $1 .{ }^{1} \mathrm{H}$ NMR (DMSO, $\left.\delta, \mathrm{ppm}\right) 6.81(\mathrm{~s}, 8 \mathrm{H}, \mathrm{Ar}-\mathbf{H})$, $5.21\left(\mathrm{~s}, 8 \mathrm{H}, \mathrm{Ar}-\mathrm{O}-\mathrm{CH}_{2}\right), 3.84$ (d, 4H, axial Ar-CH $\left.2-\mathrm{Ar}, \mathrm{J}=12.7 \mathrm{~Hz}\right), 2.95$ (d, 4H, equatorial Ar-CH2-Ar, J=12.8 Hz), 1.02 (s, 36H, Ar-CCH $).{ }^{13} \mathrm{C}$ NMR (DMSO, $\delta$, ppm) $151.4,145.1,133.2,125.1,63.0,33.6,31.0,30.7,30.4$ N.B. Tetrazole carbon not observed. $(\mathrm{m}+1) / \mathrm{z}=977.514(\mathrm{~m}+\mathrm{Na}) / \mathrm{z}=999.517$. IR $($ ATR $): \mathrm{v} / \mathrm{cm}^{-1} 3279(\mathrm{w}), 2961$ (s), 2904 (m), 2869 (m), 1780 (w) 1574 (w), 1479 (s), 1363 (m), 1302 (w), 1192 (s), $1124(\mathrm{~m}), 1006$ (m), 871 (m). Anal. Calculated for $\mathrm{C}_{52} \mathrm{H}_{64} \mathrm{O}_{4} \mathrm{~N}_{16} \cdot \mathrm{H}_{2} \mathrm{O}: \mathrm{C}, 62.75 ; \mathrm{H}$, $6.685 \% ; \mathrm{N}, 22.52$, Found C, 62.57; H, 6.45; N, $22.42 \%$. 


\section{Crystallisation of a mixed sodium / triethylammonium salt of 1}

The triethylammonium and sodium salt of the tetra-tetrazole ligand $\mathbf{1}$ was crystallised by the slow evaporation of ethanol/ethyl acetate $(50 / 50,10 \mathrm{~mL})$ from a solution of free ligand (30 mg, $0.04 \mathrm{mmol})$ and $\mathrm{Tb}\left(\mathrm{NO}_{3}\right)_{3}(\mathrm{DMSO})_{4}(21.4 \mathrm{mg}$, $0.04 \mathrm{mmol})$ along with ten equivalents of triethylamine $(51 \mu \mathrm{L})$. Clear needle-like crystals evolved which were characterised by single crystal X-ray structure determination.

\section{Crystallography}

Crystallographic data for $\mathbf{1} \cdot \mathrm{H}_{2} \mathrm{O} \cdot \mathrm{EtOH}$ and $1-\mathrm{Na}^{+} / \mathrm{HNEt}_{3}{ }^{+}$: were collected at $100(2) \mathrm{K}$ on an Oxford Diffraction Gemini diffractometer fitted with Mo Ka radiation.

Following multi-scan absorption corrections and solution by direct methods, the structures were refined against $F^{2}$ with full-matrix least-squares using the program SHELXL-97 (22). Crystallographic data for the structures reported in this paper have been deposited at the Cambridge Crystallographic Data Centre with supplementary publication numbers CCDC $1404328\left(\mathbf{1} \cdot \mathrm{H}_{2} \mathrm{O} \cdot \mathrm{EtOH}\right), 1404329\left(\mathbf{1}-\mathrm{Na}^{+} / \mathrm{HNEt}_{3}{ }^{+}\right)$. Copies of the data can be obtained free of charge on application to CCDC, 12 Union Rd, Cambridge CB21EZ, UK (fax +441223336033; email deposit@ ccdc.cam.ac.uk).

\section{Refinement details}

$\mathbf{1} \cdot \mathrm{H}_{2} \mathrm{O} \cdot \mathrm{EtOH}:$ The water molecule hydrogen atoms were refined with restrained geometries. All remaining hydrogen atoms were added at calculated positions and refined by use of a riding model with isotropic displacement parameters based on those 
of the parent atoms. Anisotropic displacement parameters were employed throughout for the non-hydrogen atoms.

1-Na ${ }^{+} / \mathrm{HNEt}_{3}{ }^{+}$: One tertiary butyl group and the triethylammonium cation were modelled as being disordered over two sets of sites with occupancies constrained to 0.5 after trial refinement. Geometries of the disordered atoms were restrained to ideal values. Water molecule hydrogen atoms were located in difference maps and refined with geometries restrained to ideal values. Hydrogen atoms on the tetrazole groups were located in difference maps. The proximity of the nitrogen atoms N312 and N215 indicates that the hydrogen is involved in an intramolecular hydrogen bond. This was modelled as being disordered between the two $\mathrm{N}$ atoms on the basis of the electron density. The hydrogen atom on N115 was assigned a site occupation of 0.5 due to hydrogen bonding to a centrosymmetrically related N115. All remaining hydrogen atoms were added at calculated positions and refined by use of a riding model with isotropic displacement parameters based on those of the parent atoms. Anisotropic displacement parameters were employed throughout for the non-hydrogen atoms.

\section{Crystal data}

1. $\mathrm{H}_{2} \mathrm{O} \cdot \mathrm{EtOH}$ : Empirical formula $\mathrm{C}_{54} \mathrm{H}_{72} \mathrm{~N}_{16} \mathrm{O}_{6}$; formula weight 1041.28 , monoclinic, space group $C c, a$ 11.5045(7), $b$ 41.964(2), $c$ 12.3762(6) $\AA, \beta$ 108.656(6) ${ }^{\circ}, V$ 5661.0(5) $\AA^{3}, Z 4, D_{c} 1.222 \mathrm{Mg} / \mathrm{m}^{3}, \mu 0.083 \mathrm{~mm}^{-1}$, crystal size 0.47 x 0.23 x $0.10 \mathrm{~mm}^{3}, \theta_{\text {min,max }}$ $3.61,30.75^{\circ}$, reflections collected 37551 , independent reflections $8252\left(R_{\text {int }} 0.0837\right)$, data/restraints/parameters 8252/4/708, goodness-of-fit on $F^{2} 0.904$, final R indices $[I>2 \sigma(I)] R_{1} 0.0636, w R_{2} 0.1323, \mathrm{R}$ indices (all data) $R_{1} 0.1192, w R_{2} 0.1483$.

1-Na ${ }^{+} / \mathrm{HNEt}_{3}{ }^{+}$: Empirical formula $\mathrm{C}_{116} \mathrm{H}_{169} \mathrm{~N}_{34} \mathrm{O}_{14} \mathrm{Na}$; formula weight 2286.84 , 
monoclinic, space group $P 2{ }_{1} / c, a$ 11.5310(4), $b$ 46.1981(12), $c$ 12.1227(3) $\AA, \beta$ 106.787(3) ${ }^{\circ}, V 6182.7(3) \AA^{3}, Z 2, D_{\mathrm{c}} 1.228 \mathrm{Mg} / \mathrm{m}^{3}, \mu 0.087 \mathrm{~mm}^{-1}$, crystal size $0.43 \mathrm{x}$ $0.12 \times 0.10 \mathrm{~mm}^{3}, \theta_{\min , \max } 3.46,26.75^{\circ}$, reflections collected 32504 , independent reflections 12953 ( $R_{\text {int }}$ 0.0443), data/restraints/parameters 12953/157/867, goodness-offit on $F^{2} 1.026$, final $\mathrm{R}$ indices $[I>2 \sigma(I)] R_{1} 0.0649, w R_{2} 0.1434$, $\mathrm{R}$ indices (all data) $R_{1}$ $0.0998, w R_{2} 0.1581$.

Photophysical Measurements

Absorption spectra were recorded at room temperature using a Perkin Elmer Lambda 35 UV/Vis spectrometer. Uncorrected steady state emission and excitation spectra were recorded using an Edinburgh FLSP980-stm spectrometer equipped with a $450 \mathrm{~W}$ xenon arc lamp, double excitation and emission monochromators, a Peltier cooled Hamamatsu R928P photomultiplier tube $(185-850 \mathrm{~nm})$. Emission and excitation spectra were corrected for source intensity (lamp and grating) and emission spectral response (detector and grating) by a calibration curve supplied with the instrument. Excited state decays $(\tau)$ were recorded on the same Edinburgh FLSP980-stm spectrometer using a microsecond flashlamp the above-mentioned R928P PMT photomultiplier as the detector. The goodness of fit was assessed by minimizing the reduced $\chi^{2}$ function and by visual inspection of the weighted residuals.

According to the approach described by Demas and Crosby (23), the luminescence quantum yield was measured in optically dilute solutions (O.D. $<0.1$ at excitation wavelength) obtained from absorption spectra on a wavelength scale [nm] and compared to the reference emitter by the following equation:

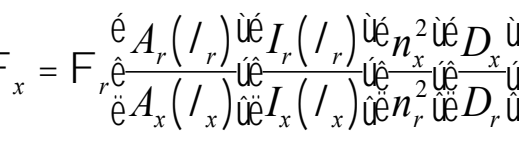


where $A$ is the absorbance at the excitation wavelength $(\lambda), I$ is the intensity of the excitation light at the excitation wavelength $(\lambda), n$ is the refractive index of the solvent, $D$ is the integrated intensity of the luminescence and $\Phi$ is the quantum yield. The subscripts $r$ and $x$ refer to the reference and the sample, respectively. The quantum yield determinations were performed at identical excitation wavelength for the sample and the reference, therefore cancelling the $I\left(\lambda_{r}\right) / I\left(\lambda_{x}\right)$ term in the equation. The reference used for the determination was an air-equilibrated $\mathrm{H}_{2} \mathrm{O}$ solution of $\left[\mathrm{Ru}(\text { bipy })_{3}\right] \mathrm{Cl}_{2}$ used as reference $\left(\Phi_{r}=0.028\right)(24)$. 


\section{Acknowledgements}

We acknowledge use of the facilities and scientific and technical assistance of the Australian Microscopy and Microanalysis Research Facility at the Centre for Microscopy,

Characterisation, and Analysis, The University of Western Australia, a facility funded by the University, State and Commonwealth Governments. D.D. gratefully acknowledges The Australian Institute of Nuclear Scientists and Engineers (AINSE) Ltd for provision of a postgraduate research award (AINSE PGRA 2012).

\section{References}

(1) Gutsche, C. D., Calixarenes: An Introduction. 2nd ed.; RSC Publishing: Cambridge, 2008.

(2) Lincheneau, C.; Quinlan, E.; Kitchen, J. A.; McCabe, T.; Matthews, S. E.; Gunnlaugsson, T., Supramol. Chem. 2013, 25, 869-880.

(3) Horvat, G.; Stilinovic, V.; Kaitner, B.; Frkanec, L.; Tomisic, V., Inorg. Chem. 2013, 52, 12702-12712.

(4) Horvat, G.; Stilinovic, V.; Hrenar, T.; Kaitner, B.; Frkanec, L.; Tomisic, V., Inorg. Chem. 2012, 51, 6264-6278.

(5) Ennis, B. W.; Muzzioli, S.; Reid, B. L.; D'Alessio, D. M.; Stagni, S.; Brown, D. H.; Ogden, M. I.; Massi, M., Dalton Trans. 2013, 42, 6894-6901.

(6) Hwang, D.; Lee, E.; Jung, J. H.; Lee, S. S.; Park, K. M., Crystal Growth \& Design 2013, 13, 4177-4180.

(7) Redshaw, C.; Rowe, O.; Hughes, D. L.; Fuller, A. M.; Ibarra, I. A.; Humphrey, S. M., Dalton Trans. 2013, 42, 1983-1986.

(8) Brancatelli, G.; De Zorzi, R.; Hickey, N.; Siega, P.; Zingone, G.; Geremia, S., Crystal Growth \& Design 2012, 12, 5111-5117.

(9) Gramage-Doria, R.; Armspach, D.; Matt, D., Coord. Chem. Rev. 2013, 257, 776816.

(10) Semeril, D.; Matt, D., Coord. Chem. Rev. 2014, 279, 58-95.

(11) Pinter, T.; Jana, S.; Courtemanche, R. J. M.; Hof, F., J. Org. Chem. 2011, 76, 3733-3741.

(12) Boyko, V.; Rodik, R.; Danylyuk, O.; Tsymbal, L.; Lampeka, Y.; Suwinska, K.; Lipkowski, J.; Kalchenko, V., Tetrahedron 2005, 61, 12282-12287.

(13) Dondoni, A.; Marra, A., Tetrahedron 2007, 63, 6339-6345. 
(14) Chen, Y. J.; Chung, W. S., Eur. J. Org. Chem. 2009, 4770-4776.

(15) D'Alessio, D.; Muzzioli, S.; Skelton, B. W.; Stagni, S.; Massi, M.; Ogden, M. I., Dalton Trans. 2012, 41, 4736-4739.

(16) D'Alessio, D.; Sobolev, A. N.; Skelton, B. W.; Fuller, R. O.; Woodward, R. C.; Lengkeek, N. A.; Fraser, B. H.; Massi, M.; Ogden, M. I., J. Am. Chem. Soc. 2014, 136, 15122-15125.

(17) Collins, E. M.; Mckervey, M. A.; Madigan, E.; Moran, M. B.; Owens, M.; Ferguson, G.; Harris, S. J., Journal of the Chemical Society-Perkin Transactions 1 1991, 3137-3142.

(18) Halouani, H.; Dumazet-Bonnamour, I.; Perrin, M.; Lamartine, R., J. Org. Chem. 2004, 69, 6521-6527.

(19) Koguro, K.; Oga, T.; Mitsui, S.; Orita, R., Synthesis-Stuttgart 1998, 910-914.

(20) Eliseeva, S. V.; Bunzli, J. C. G., Chem. Soc. Rev. 2010, 39, 189-227.

(21) Beer, P. D.; Drew, M. G. B.; Ogden, M. I., J. Chem. Soc., Dalton Trans. 1997, 1489-1491.

(22) Sheldrick, G. M., Acta Crystallographica Section A 2008, 64, 112-122.

(23) Crosby, G. A.; Demas, J. N., J. Phys. Chem. 1971, 75, 991-1024.

(24) Nakamaru, K., Bull. Chem. Soc. Jpn. 1982, 55, 2697-2705. 